\title{
К ВОПРОСУ ОБРАБОТКИ РЕЗУЛЬТАТОВ ГЕОТЕХНИЧЕСКОГО МОНИТОРИНГА ЗА ОСАДКАМИ СООРУЖЕНИЙ
}

\author{
Кулешов Александр Петрович', \\ kuleshov@inzhgeos.ru \\ Пендин Вадим Владимирович', \\ pendin@yandex.ru \\ Российский государственный геологоразведочный университет им. Серго Орджоникидзе, \\ Россия, 117997, г. Москва, ул. Миклухо-Маклая, 23.
}

Актуальность работы обусловлена обеспечением сохранности существующей застройки, находящейся в зоне влияния нового строительства. После того, как выявлены инженерно-геологические процессы, негативно влияющие на условия функционирования сооружения, и определены параметры, от которых зависит развитие таких процессов, возникает необходимость оценки уровня рисков. В последнее время наиболее часто используется корреляционно-регрессионный анализ данных режимных наблюдений, основанный на вероятностно-статистической группе методов - закономерно случайном характере развития процесСов во времени и пространстве.

Цель: статистический анализ характеристик величин деформаций зданий, возникающих под влиянием нового строительства, нахождение и описание связи между осадочными марками и деформационными знаками, расположенными на зданиях, оценка режима функционирования элементарных природно-технических систем в сложных инженерно-геологических условиях, анализ накопленной инженерно-геологической информации по объекту, в том числе результаты предпостроечных изысканий. Методы: анализ режимных наблюдений с помощью автокорреляционной функции, сравнение результатов с данными натурных многолетних наблюдений, представление объекта исследования в виде сложной системы, состоящей из совокупности элеменТов, между которыми существуют связи и взаимодействия, установление совокупности опасности, выделение зон риска для определенного объекта в виде возможных потерь во времени, оценка уязвимости поражаемых объектов от каждого из выявленных процессов, прогноз развития техноприродных опасностей в пространстве, деформационная съемка.

Результаты. Один из важнейших компонентов обеспечения надежной и безопасной эксплуатации любого сооружения - система мониторинга. На основе данных, полученных в ходе реализации литомониторинга, осуществляется контроль за состоянием системы посредством сравнения значений наблюдаемых показателей со стандартной системой критериев, а также вырабатываются управляющие решения по оптимизации ее функционирования. Анализ всех собранных материалов, а также результатов диагностики состояния литотехнической системы на текущий момент времени, позволяет выявить парагенезис инженерно-геологических процессов, определяющих возможность развития экстремальных ситуаций, создающих угрозу безопасной эксплуатации объекта. Целесообразно построение карт разностей, отражающих изменения показателей свойств взаимодействия технического объекта и геологического тела и определяющих направление дальнейшего развития состояния системы.

\section{Ключевые слова:}

Геотехнический мониторинг, система наблюдений, корреляционный анализ, грунт,

напряженно-деформированное состояние, процесс деформации, осадки сооружений, режимные наблюдения.

\section{Введение}

Для современного этапа экономического и общественного развития в России характерно расширение строительного производства и проведение масштабного строительства в крупных городах, сопровождающееся постоянным ростом сложности возводимых объектов и условий, в которых осуществляется их строительство [1]. Это неизбежно порождает новые задачи, связанные с обеспечением безопасной жизнедеятельности в условиях мегаполиса, определяющейся, во-первых, надежностью самих строящихся сооружений, и, во-вторых, влиянием проводимого строительства на уже существующую инфраструктуру [2].

Пренебрежение безопасностью может привести к проявлению в ранее построенных зданиях трещин в стенах, перекосов, сдвигу плит перекрытий, разрушению конструкций, т. е. нарушению нормальной эксплуатации зданий, к авариям, а в некоторых случаях даже к катастрофам.

Опасность возникновения подобных явлений увеличивается при сочетании плотной окружаю- щей застройки с наличием сложных инженерногеологических условий в местах нового строительства или реконструкции зданий и сооружений изза возможного развития целого ряда негативных и техногенных процессов [3].

Поэтому новое строительство или реконструкция уже существующих зданий сопровождаются обследованием этих зданий в зоне влияния нового строительства, организацией наблюдений за поведением строящегося или реконструируемого здания и окружающей его существующей застройки [4].

При этом очевидно, что контроль технического состояния несущих конструкций должен носить систематический характер и позволять осуществлять оценку происходящих изменений на основе количественных критериев, т. е. базироваться на процедурах выявления соответствия фактической прочности, жесткости и устойчивости конструктивных элементов нормативным требованиям [5].

В настоящее время в крупных мегаполисах (например, г. Москва, Санкт-Петербург, Новосибирск, Красноярск) проводятся работы по обсле- 
дованию технического состояния отдельных объектов. Однако большое количество зданий и сооружений не охвачено вообще никаким контролем, хотя жизнедеятельность города динамично приводит как к ухудшению свойств грунтов, так и к негативным воздействиям силового и не силового характера на наземные конструкции зданий и сооружений [6]. Все это в условиях исчерпания нормативных сроков эксплуатации большого количества объектов недопустимо и требует системно организованных наблюдений.

Всем этим обусловлено появление в нормативных документах указаний, регламентирующих проведение геотехнического мониторинга на объектах нового строительства и реконструкции [7].

Появление геотехнического мониторинга в перечне работ, сопровождающих строительство, обусловлено особенностями развития урбанизированных территорий.

Организация режимных наблюдений (геотехнического мониторинга) за состоянием лито-технической системы, в совокупности с квалифицированным анализом получаемой в процессе мониторинга информации, позволяют своевременно принять верное управленческое решение и избежать непредвиденных экономических потерь [8].

В нормативных документах существует несколько определений геотехнического мониторинга.

В соответствии с СП 305.1325800.2017 «Здания и сооружения. Правила проведения геотехнического мониторинга при строительстве» [9] и СП 22.13330 .2016 Основания зданий и сооружений» [10], геотехнический мониторинг - комплекс работ, основанный на натурных наблюдениях за поведением конструкций вновь возводимого или реконструируемого сооружения, его основания, в т. ч. грунтового массива, окружающего (вмещающего) сооружение, и конструкций сооружений окружающей застройки.

В соответствии с ТСН 50-304-2001 г. Москвы (МГСН 2.07-01) «Основания, фундаменты и подземные сооружения» [11]: «Геотехнический мониторинг - система наблюдений и контроля за состоянием и изменением грунтовых, природных и техногенных условий в процессе строительства и эксплуатации объекта» .

Другим документом, регламентирующим организацию режимного контроля за состоянием строящихся и существующих зданий и сооружений, a также вмещающим его грунтовым массивом, является «Правила подготовки и производства земляных работ, обустройства и содержания земляных площадок в городе Москве», однако в этом документе данный комплекс наблюдений определяется как «система инженерного мониторинга».

Необходимость проведения мониторинга существующей застройки, попадающей в зону влияния нового строительства, регламентируется «Инструкцией по наблюдениям за движениями земной поверхности и расположенными на ней объектами при строительстве в Москве подземных сооруже- ний», а также Постановлением Правительства Москвы № 857-ПП от 7 декабря 2004 г.

Помимо отраслевых нормативных документов и регионального законодательства, необходимость проведения мониторинга с 2009 г. прописана на федеральном уровне в ФЗ № 384 «Технический регламент о безопасности зданий и сооружений» .

Несмотря на разные названия и формулировки, суть требований и цель производства работ по геотехническому (инженерному) мониторингу остается одинаковой - предупреждение возникновения аварийных ситуаций [12].

В соответствии с требованиями СП 22.13330.2016 и п. 6.1 ГОСТ 31937-2011 [13] геотехнический мониторинг осуществляется в период проведения реконструкции сооружения и на начальном этапе эксплуатации реконструируемого объекта.

Цель настоящей работы: оценка влияния нового строительства на соседние существующие здания и сооружения, прогноз изменения в сложных инженерно-геологических условиях и корреляционный анализ данных мониторинговых наблюдений.

В задачи исследования входило: проведение анализа результатов наблюдений по режимным сетям мониторинга с целью его оптимизации, применение и оценка корреляционного метода в рамках геотехнического мониторинга, качественное рассмотрение оценки вероятности риска развития негативных инженерно-геологических процессов.

Предметом исследования является взаимодействие между структурными элементами локальной природно-технической системы «сооружение-основание-грунт» [14].

Для организации работ по выполнению инструментального геодезического мониторинга за осадками фундаментов, кренами и горизонтальными перемещениями отдельных конструкций окружающих зданий в период строительства создана система геотехнического мониторинга, состоящая из стенных и плитных марок, установленных на несущих стенах по периметру и подвальной части зданий, на опорах теплотрассы и ограждающих конструкциях локальной литотехнической системы в условиях стесненной городской застройки, в районе строительства многофункционального делового центра с подземной автостоянкой по адресу: г. Москва, ул. Большая Садовая, д. 5, стр. 1, 2; ул. 2-я Брестская, д. 1, стр. 1; ул. Гашека, вл. 12 часть стр. 1 (подъезды 1-4), стр. 5-7.

\section{Конструктивные особенности сооружений}

Рассматриваемая локальная литотехническая система взаимодействия «основание-грунт» состоит из следующих составных частей (рис. 1):

- многофункциональный деловой центр с подземной автостоянкой;

- здание по адресу: ул. Гашека, д. 12, стр. 2;

- здание по адресу: ул. Гашека, д. 12, стр. 8;

- здание по адресу: ул. Большая Садовая, д. 5, стр. 1, 2. 
Проектируелый многофункииональный деловой иентр с подземной автостоянкой состоит из трех корпусов: корпус № 1 и 2 - апартаменты (12 этажей), корпус № 3 - административное здание (6 этажей). Проектом под зданиями предусмотрен 3-этажный подземный паркинг с заглублением 13,4 м для технических и вспомогательных помещений гостиницы. Здания с габаритами в плане $68,0 \times 61,0$ м (высота этажей $h=3,8-5,6$ м) и $151,0 \times 79,0$ м (высота этажей $h=3,6 \mathrm{~m})$.

Здание по адресу: ул. Гашека, д. 12, стр. 2 - административное, в настоящее время в здании расположено Главное Архитектурно-планировочное управления г. Москвы, 5-ти этажное с выносным подвалом и техническим этажом. Год постройки здания 1953. Последняя реконструкция производилась в 70-х гг. 20-го в. Основные габариты здания в плане $12,3 ? 61,6$ м. Минимальное расстояние от здания до ограждения котлована строящегося объекта составляет $~ 6,1 \mathrm{~m}$.

Здание по адресу: ул. Гашека, д. 12, стр. 8 - административное, согласно планам БТИ, 2-х этажное с мансардой, надстройкой над мансардой и подвалом под частью здания, здание прямоугольное в плане, в здании имеются две двухмаршевые железобетонные лестницы, ведущие с первого этажа на мансарду. Минимальное расстояние от существующего здания до ограждения котлована строящегося объекта составляет $\sim 6,0 \mathrm{M}$.

Здание гостиничного колплекса «Пекин» по адресу ул. Большая Садовая, д. 5, стр. 1, 2 спроектировано архитектором Д.Н. Чечулиным в конце 30-х гг. XX в. Работы по строительству здания начались в 1939 г. и закончились в 1958 г. Статус здания - «старое». Фундаменты здания под наружными и внутренними несущими стенами ленточные, из монолитного железобетона. Минимальное расстояние от здания до ограждения котлована строящегося объекта составляет 17,3 м.

\section{Краткая инженерно-геологическая характеристика участка}

В геолорфологическол отношении участок расположен в пределах древнеаллювиальной террасы p. Москвы [15]. Рельеф площадки относительно ровный, характеризуется абсолютными высотными отметками поверхности порядка 153,15...154,25 м.

В геологическол отношении с уровня дневной поверхности, под щебнем и асфальтобетонным покрытием, до глубины 2,3...5,5 м участок перекрыт насыпными грунтами (tQ $\mathrm{IV}$ ). Насыпные грунты преимущественно песчано-глинистого состава, с включением строительного мусора.

Под насыпными грунтами залегают верхнечетвертичные древнеаллювиальные отложения ( $\left.\mathrm{aQ}_{\text {III }}\right)$, представленные песками от пылеватых до крупных, рыхлыми, средней плотности и плотными, средней степени водонасыщения и насыщенными водой и гравийными и гравийно-галечниковыми грунтами, насыщенными водой, общей мощностью $3,0 \ldots 8,4 \mathrm{M}$.

Комплекс четвертичных древнеаллювиальных отложений на глубине 7,8...11,2 м подстилается верхнеюрскими породами, представленными следующими ярусами: волжским $\left(\mathrm{J}_{3} \mathrm{v}\right)$; оксфордским $\left(\mathrm{J}_{3} \mathrm{Ox}\right)$.

Верхнеюрские породы волжского яруса $\left(\mathrm{J}_{3} \mathrm{v}\right)$ представлены песками пылеватыми, средней плотности и плотными, средней степени водонасыщения, супесями пластичной консистенции, суглинками и глинами от мягкопластичной до полутвердой консистенции, общей мощностью 5,7... 9,5 м.

Верхнеюрские породы оксфордского яруса $\left(\mathrm{J}_{3} \mathrm{Ox}\right)$ представлены глинами твердой и полутвердой консистенции, мощностью $6,5 . .9,0$ м. Под верхнеюрскими отложениями, на глубине $23,1 . . .26,0$ м и залегают породы касимовского яруса верхнего отдела каменноугольной системы $\left(\mathrm{C}_{3} \mathrm{ks}\right)$, представленного следующими подсвитами
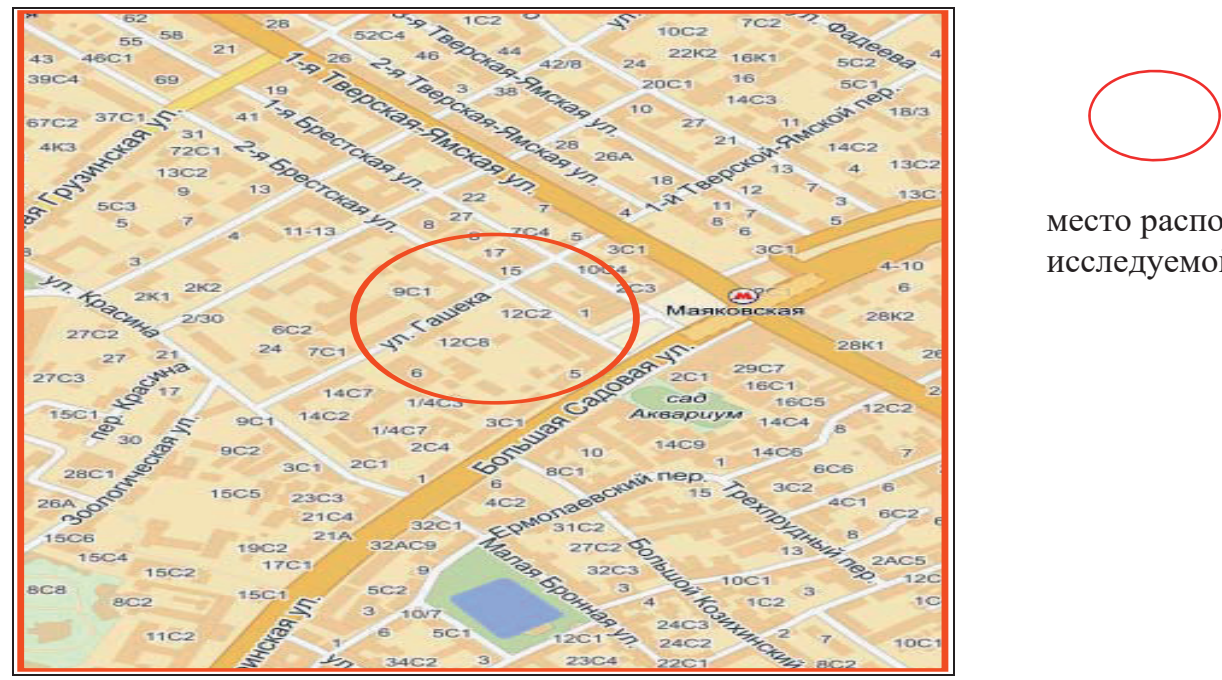

место расположения исследуемой площадки

Puс.1. Ситуаиионный план территории исследований

Fig. 1. Situational plan of the research area 
(сверху вниз): измайловской $\left(\mathrm{C}_{3} \mathrm{izm}\right)$; мещеринской $\left(\mathrm{C}_{3} \mathrm{msc}\right)$; перхуровской $\left(\mathrm{C}_{3} \mathrm{pr}\right)$; неверовской $\left(\mathrm{C}_{3} \mathrm{nv}\right)$; ратмировской $\left(\mathrm{C}_{3} \mathrm{rt}\right)$; воскресенской $\left(\mathrm{C}_{3} \mathrm{vs}\right)$.

Гидрогеологические условия участка характеризуются наличием надъюрского и трех верхнекаменноугольных водоносных горизонтов - измайловского, перхуровского и ратмировского [16].

\section{Организация мониторинга}

В состав работ по геотехническому мониторингу входит: проектируемое новое строительство комплекса зданий; ограждение котлована «стена в грунте»; здания окружающей застройки; инженерные коммуникации.

Для организации работ по геодезическому мониторингу на несущих стенах по периметру зданий окружающей застройки и на опорах теплотрассы были установлены осадочные и деформационные марки (рис. 3). Ситуационный план окружающей застройки, попадающей в зону влияния нового строительства, представлен на рис. 2.

Методика инструментальных геодезических наблюдений заключается в периодическом (по циклам) высокоточном нивелировании стенных марок по программе II класса двойными ходами «прямо» и «обратно» [17].

Работы по геотехническому мониторингу выполнялись посредством визуально-инструментального наблюдения за техническим состоянием окружающей застройки и наблюдением за осадками посредством геодезических измерений перемещений деформационных марок, установленных на ограждающие конструкции.

В каждом цикле наблюдений вычисляются отметки всех установленных марок. По разности отметок одноименных марок в смежных циклах измерений получают осадки марок, которые выписываются в сводные таблицы с нарастающим итогом за весь период наблюдений (раз в месяц) [18]. При выполнении наблюдений использовался высокоточный цифровой нивелир Trimble DINI 12 и комплект штрихкодовых нивелирных реек с инварной полосой. Нивелирная сеть строилась в виде системы полигонов, схема которых одинакова во всех циклах наблюдений. Невязки в полигонах ни-

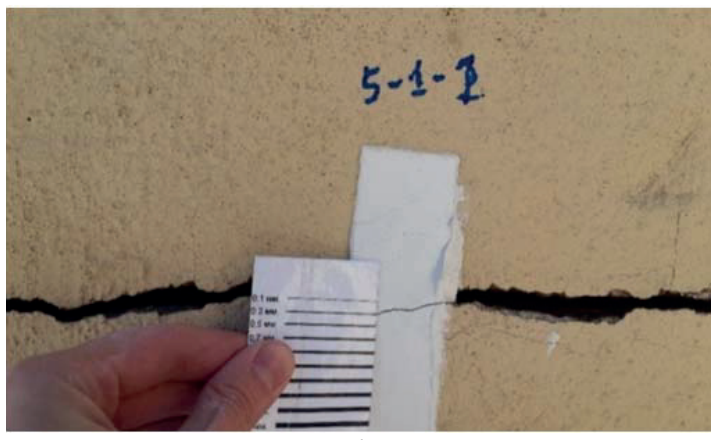

$a / a$ велирной сети не превышают величин, вычисленных по формуле $\mathrm{Fh}= \pm 0,5 \mathrm{mм} \sqrt{n}$, где $n-$ количество штативов в полигонах. После выполнения полевых измерений все данные нивелирования обрабатываются по компьютерной программе строгого уравновешивания STAR*LEV [19].

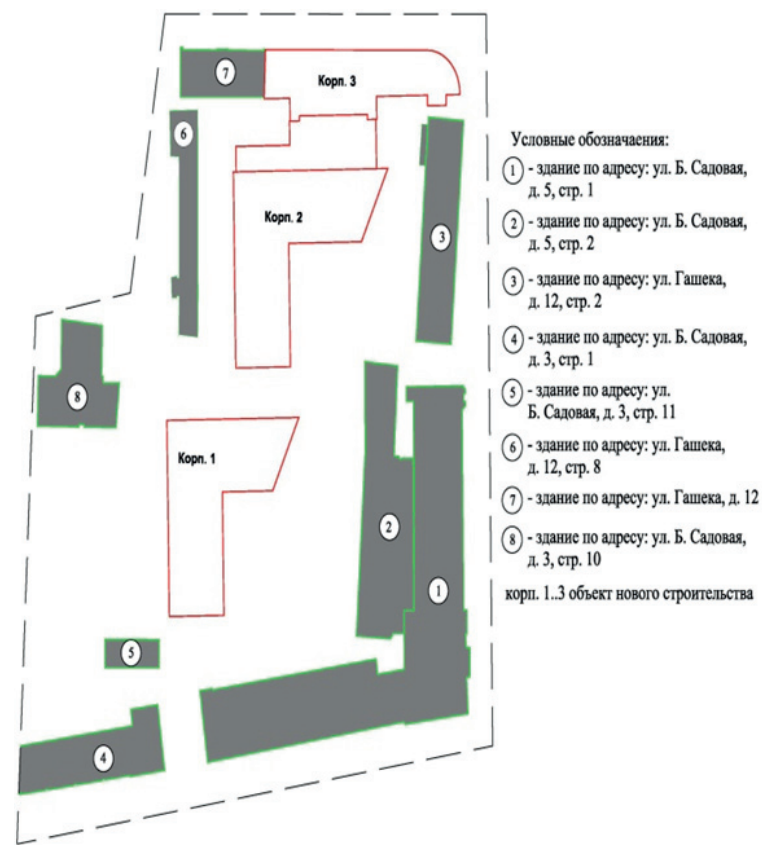

Puс. 2. Ситуационный план окружающей застройки, попадающей в зону влияния объекта нового строительства: «Реставрация с приспособлением к современныл требованиял гостиничного комплекса «Пекин» и застройка прилегающей территории»

Fig. 2. Situational plan of the surrounding buildings, which fall into the zone of influence of the new construction object: «Restoration with adaptation to modern requirements of the hotel complex «Beijing» and the construction of the adjacent territory»

При обследовании строительных конструкций производилось изучение трещин, выявление причин их возникновения и динамики развития [20]. На каждой трещине устанавливался маяк, который при развитии трещины разрывается. Маяк устанавливался в местах наибольшего развития трещины (фото).

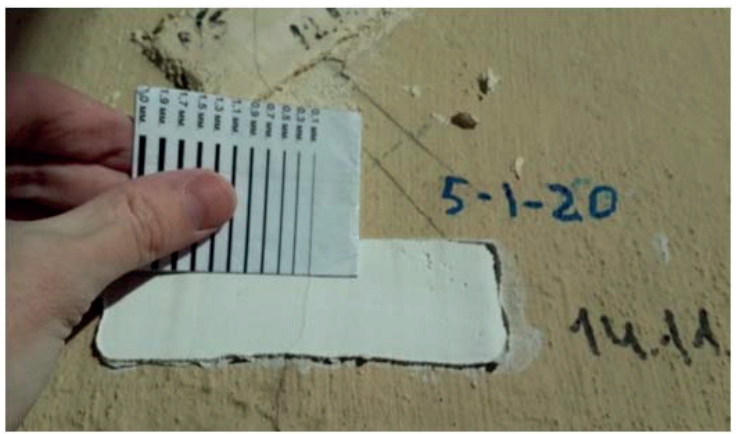

$\sigma / b$

Фото. Фотофиксаиия гипсовых маяков №5-1-1 (а) и 5-1-20 (б), установленных на ограждающие конструкции здания по адресу: ул. Большая Садовая, 2. 5, стр. 1

Photo. Photofixation of gypsum beacons № 5-1-1 (a) and 5-1-20 (b), installed on the building envelope at Bolshaya Sadovaya street, 5, bld.1 


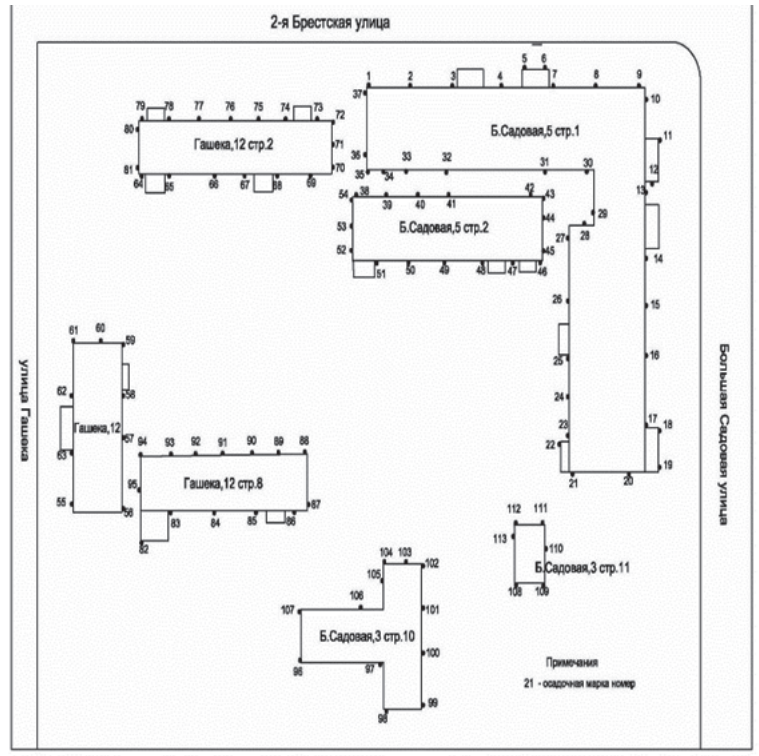

$a / a$

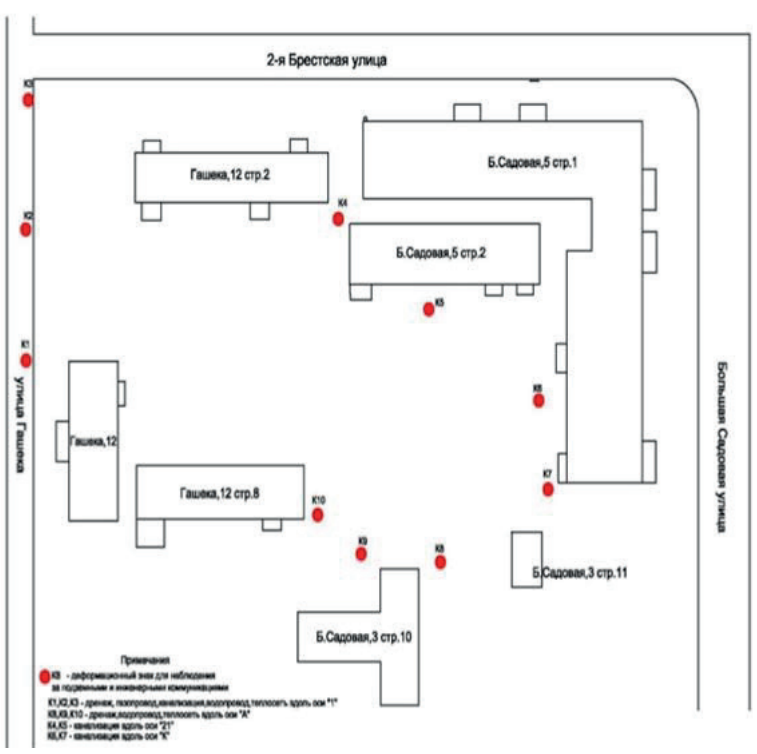

$\sigma / b$

Pис.3. Схема расположения осадочных (а) марок и деформационных знаков (б) на существующих зданиях

Fig. 3. Layout of sedimentary (a) marks and deformation signs (b) on existing buildings

\section{Результаты исследования и их обсуждение}

За весь период инженерно-геодезических изысканий (ноябрь 2014 г. - апрель 2017 г.) по контролируемым деформационным маркам в общем объеме не зафиксировано превышение предельно допустимого значения осадки фундаментов наблюдаемых зданий (рис. 4). Исключение составляют подземные инженерные коммуникации, расположенные в зоне влияния объекта нового строительства. С учетом стабилизации осадок дальнейший геотехнический мониторинг за зданиями окружающей застройки и подземными инженерными коммуникациями является нецелесообразным и допускается не осуществлять.

Раскрытие трещин вызвано неравномерностью осадок зданий. Наличие трещин шириной раскрытия 0,5 мм и менее свидетельствует об изменении температурно-влажностного режима и не носит негативный характер. Все полученные значения соответствуют требованиям нормативно-технических и проектных документов.

Результаты выполненного инструментального геотехнического мониторинга приведены на рис. 4-7.

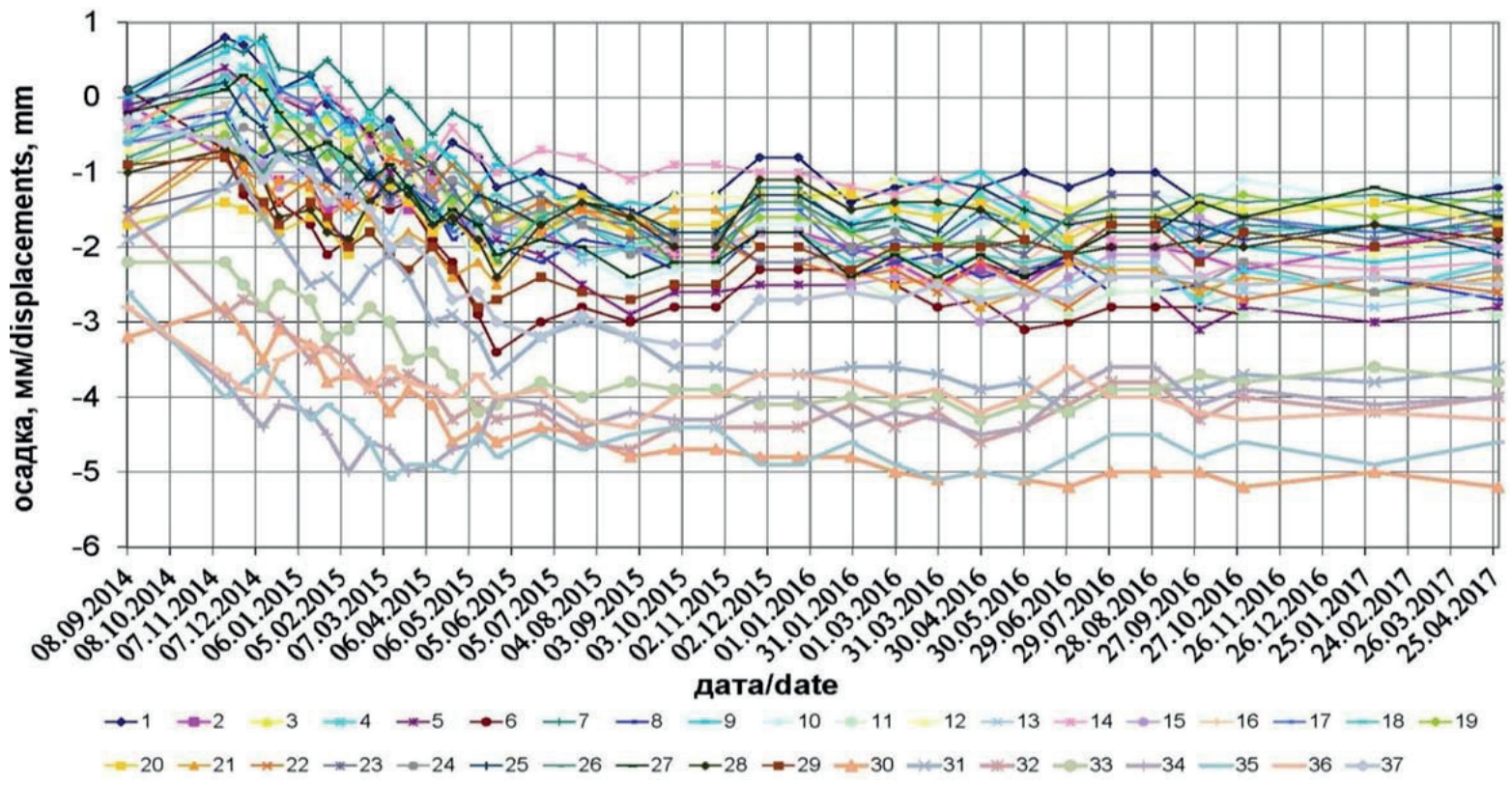

Рис. 4. График осадок деформационных марок, установленных на здании по адресу: ул. Большая Садовая д. 5 стр. 1

Fig. 4. Graph of accumulated settlements of the deformation marks installed on the building at Bolshaya Sadovaya street, 5, bld.1 

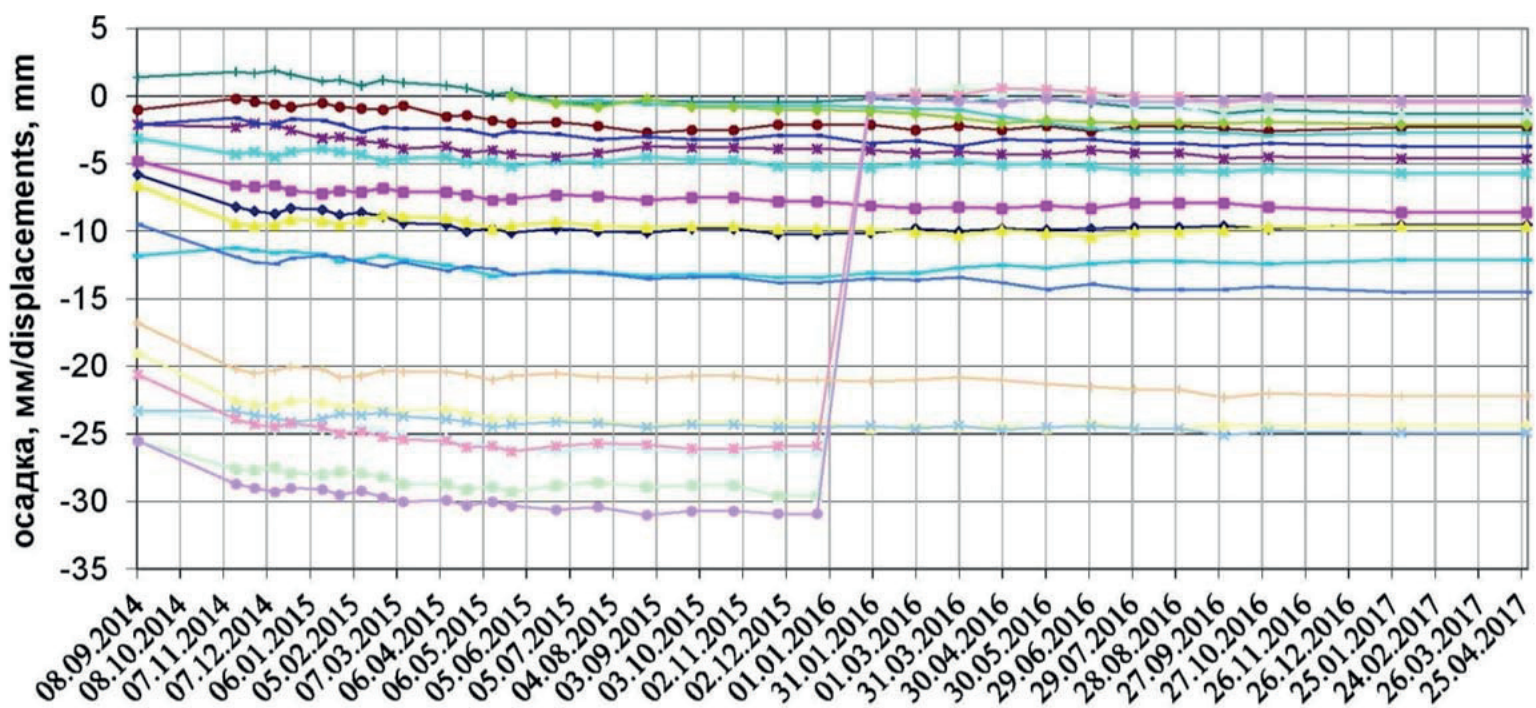

дата/date, $\mathrm{mm}$

$\rightarrow 38 \rightarrow-39 \div 40 \div 41 \div 42 \rightarrow 43+44-45-46 \quad 47 \div 48 \quad 49 \rightarrow 50 \div 51 \rightarrow 52 \div 53-54 \rightarrow 52 a \rightarrow 526$

Pис. 5. График осадок деформационных марок, установленных на здании по адресу: ул. Большая Садовая д. 5 стр. 2

Fig. 5. Graph of accumulated settlements of the deformation marks installed on the building at Bolshaya Sadovaya street, 5, bld. 2

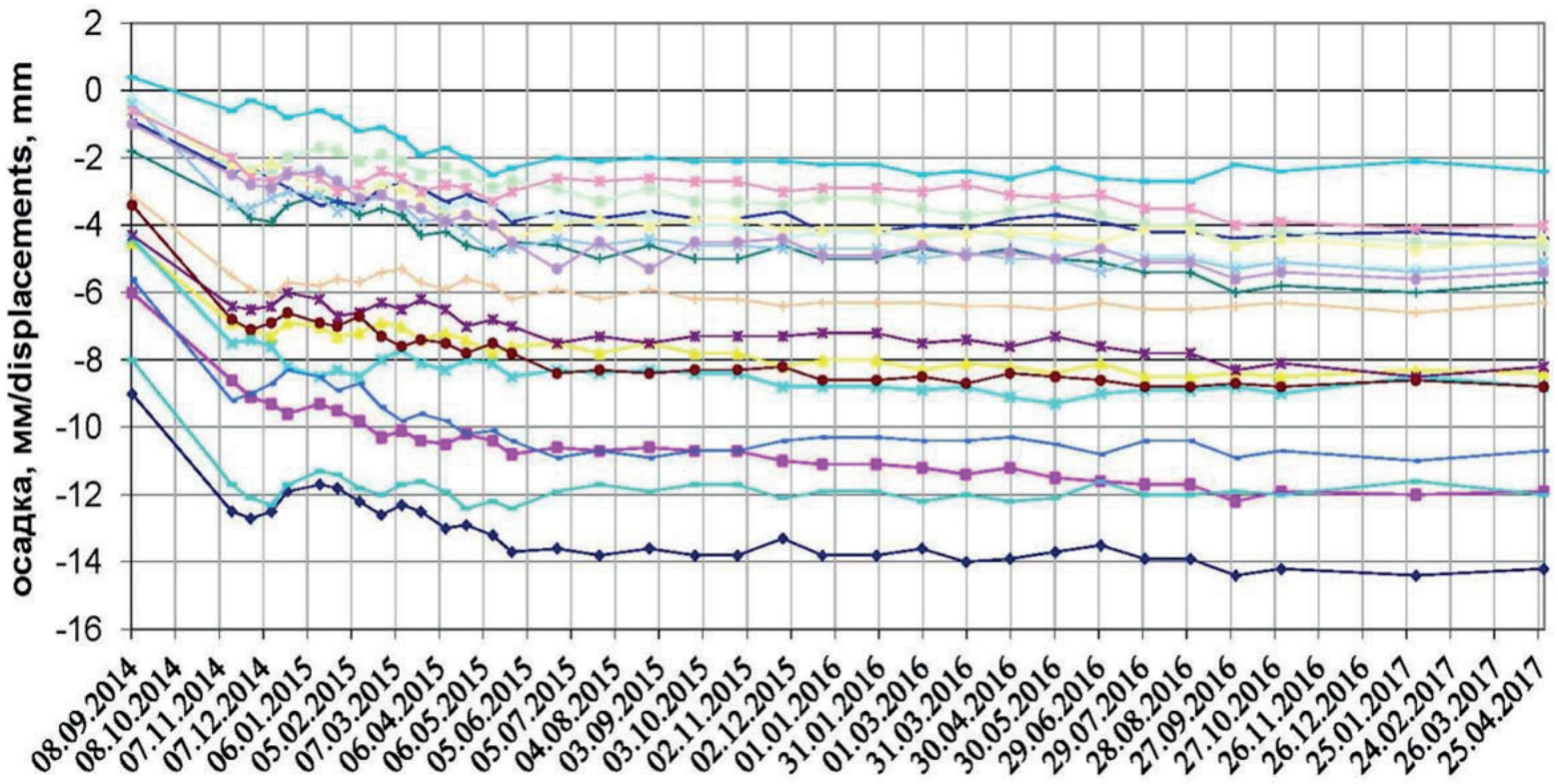

дата/date, $\mathrm{mm}$

$\rightarrow-64 \rightarrow-65 \div 66 \div-67 * 68 \rightarrow-69+70-71-72 \div 73 \div 74 \quad 75 \div-76 \div-77 \rightarrow-78 \div-79-80-81$

Pис. 6. График осадок деформационных марок, установленных на здании по адресу: ул. Гашека, д. 12, стр. 2

Fig. 6. Graph of accumulated settlements of the deformation marks installed on the building at 12, Gashek street, bld. 2

Осредненные суммарные осадки большинства стенных марок для рассматриваемых зданий по результатам инструментальных геодезических наблюдений (мониторинга) за окружающей застройкой приведены в табл. 1 .

Для здания по адресу: ул. Гашека, д. 12, стр. 2 , максимальная осадка деформационных марок составляет 14,2 мм (марка № 64), максимальная величина раскрытия трещин на контролируемых гипсовых маяках не превышает 0,3 мм. По результатам анализа установлено что с «нулевого» цикла измерений до настоящего времени максимальный прирост осадок составил 5,9 мм (марка № 65).

Для здания по адресу: ул. Большая Садовая, д. 5, стр. 2, максимальная осадка деформационных марок составляет 24,9 мм (марка № 50), максимальная величина раскрытия трещин на контролируемых гипсовых маяках не превышает 0,1 мм. По результатам анализа установлено что с «нулевого» цикла измерений до настоящего времени максимальный прирост осадок составил 5,4 мм (марка № 53). 


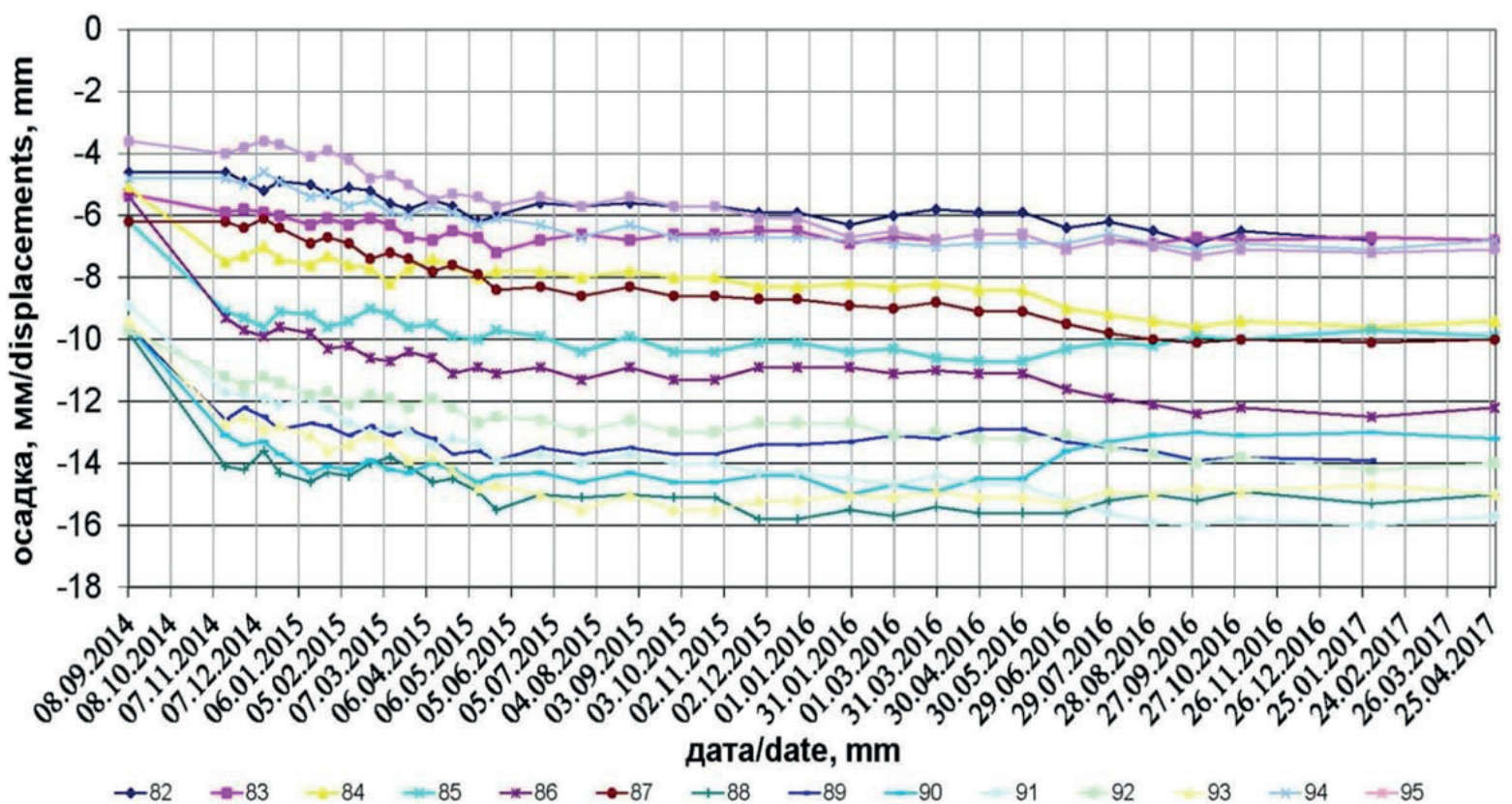

Рис. 7. График осадок деформащионных марок, установленных на здании по адресу: ул. Гашека, д. 12, стр. 8

Fig. 7. Graph of accumulated settlements of the deformation marks, installed on the building at Gashek stereet, 12, bld. 8

Таблица 1. Осредненные сумларные осадки зданий

Table 1. Average total building settlement

\begin{tabular}{|c|c|c|}
\hline \multirow{2}{*}{$\begin{array}{c}\text { Наименование объекта } \\
\text { (здание по адресу) } \\
\text { Object name (building at) }\end{array}$} & $\begin{array}{c}\text { Осредненная суммарная осадка, мм } \\
\text { Averaged total settlement, mm }\end{array}$ \\
\cline { 2 - 3 } & $\begin{array}{c}\text { Без учета нового } \\
\text { строительства } \\
\text { Without regard to } \\
\text { new construction }\end{array}$ & $\begin{array}{c}\text { С учетом нового } \\
\text { строительства } \\
\text { Taking into account } \\
\text { new construction }\end{array}$ \\
\hline $\begin{array}{c}\text { ул. Гашека, д. 12, стр. 2 } \\
\text { Gashek street, 12, bld. 2 }\end{array}$ & 5,2 & 7,2 \\
\hline $\begin{array}{c}\text { ул. Гашека, д. 12, стр. 8 } \\
\text { Gashek street, 12, bld. 8 }\end{array}$ & 6,0 & 11,1 \\
\hline $\begin{array}{l}\text { ул. Большая Садовая, д. 5, стр. 1 } \\
\text { Воlshaya Sadovaya street, 5, bld. 1 }\end{array}$ & 1,2 & 2,1 \\
\hline $\begin{array}{l}\text { ул. Большая Садовая, д. 5, стр. 2 } \\
\text { Воlshaya Sadovaya street, 5, bld. 2 }\end{array}$ & 4,8 & 7,9 \\
\hline
\end{tabular}

Для здания по адресу: ул. Большая Садовая, д. 5, стр. 1, максимальная осадка деформационных марок составляет 5,2 мм (марка № 30), максимальная величина раскрытия трещин составляет 0,5 мм (ГМ 5-1-11). Согласно геодезическим наблюдениям, на марках, установленных в области данного гипсового маяка, зафиксированы максимальные значения осадок и по результатам анализа установлено, что с «нулевого» цикла измерений до настоящего времени максимальный прирост осадок составил 3,0 мм (марка № 6).

Для здания по адресу: ул. Гашека, д. 12, стр. 8 , максимальная осадка деформационных марок составляет -15,7 мм (марка № 91), максимальная величина раскрытия трещин на контролируемых гипсовых маяках не превышает 0,3 мм. По результатам анализа установлено что с «нулевого» цикла измерений до настоящего времени максимальный прирост осадок составил 6,8 мм (марки № 86 и 91).
За весь период инженерно-геодезических изысканий по контролируемым деформационным маркам в общем объеме не зафиксировано превышение предельно допустимого значения осадки фундаментов наблюдаемых зданий. Исключение составляют подземные инженерные коммуникации, расположенные в зоне влияния объекта нового строительства.

\section{Анализ данных мониторинговых наблюдений} методом корреляционно-регрессионного анализа

В научных исследованиях часто возникает необходимость в нахождении связи между результативными и факторными переменными, т. е. описанием совокупности взаимосвязей. Вторые представляют собой признаки, способствующие изменению таковых, связанных с первыми [21].

Если эти зависимости стохастичны, а анализ осуществляется по выборке из генеральной совокупности, то данная область исследований относится к задачам статистического исследования зависимостей [22], которые включают в себя корреляционный, регрессионный, дисперсионный, ковариационный анализ и анализ таблиц сопряженности.

Корреляционный анализ - это метод, применяющийся с целью проверки гипотезы о статистической значимости двух и более переменных, если исследователь их может измерять, но не изменять. Корреляционная зависимость - это изменения, которые вносят значения одного признака в вероятность появления разных значений другого признака [23]. 
Цель анализа состоит в обеспечении получения некоторой информации об одной переменной с помощью другой переменной. Переменные коррелируются, когда возможно достижение цели.

Задачи корреляционного анализа сводятся $\mathrm{k}$ выделению важнейших факторов, которые влияют на результативный признак, измерению тесноты связи между факторами, выявлению неизвестных причин связей и оценке факторов, оказывающих максимальное влияние на результат.

Обязательное условие - массовость значений изучаемых показателей, что позволяет выявить тенденцию, закономерность развития, форму взаимосвязи между признаками.

Количественная оценка тесноты взаимосвязи двух случайных величин осуществляется с помощью коэффициента корреляции. Значение коэффициента корреляции может изменяться в диапазоне от -1 до +1 . Абсолютное значение коэффициента корреляции показывает силу взаимосвязи.

Чем меньше его абсолютное значение, тем слабее связь [24]. Если он равен нулю, то связь вообще отсутствует.

Чем больше значение модуля коэффициента корреляции, тем сильнее связь и тем меньше разброс в значениях при каждом фиксированном значении. Знак коэффициента корреляции определяет направленность взаимосвязи: минус - отрицательная, плюс - положительная [25].

Достаточно условно может быть использована следующая классификация взаимосвязей по значению коэффициента корреляции (табл. 2). Данная классификация не является строгой.

C помощью программных средств (MS Excel) произвели многофакторный корреляционный анализ для рассматриваемых выше зданий и сооружений, результаты которого представлены в виде матрицы коэффициентов корреляции (табл. 3-6).
Таблииа 2. Интерпретация значений коэффициента корреляиии

Table 2. Interpretation of the correlation coefficient values

\begin{tabular}{|c|l|}
\hline$r=1$ & $\begin{array}{l}\text { Функциональная зависимость } \\
\text { Perfect linear relationship }\end{array}$ \\
\hline $0,7 \leq r \leq 0,99$ & $\begin{array}{l}\text { Сильная статическая взаимосвязь } \\
\text { Strong linear relationship }\end{array}$ \\
\hline $0,5 \leq r \leq 0,69$ & $\begin{array}{l}\text { Седняя статическая взаимосвязь } \\
\text { Moderate relationship }\end{array}$ \\
\hline $0,20 \leq r \leq 0,49$ & $\begin{array}{l}\text { Слабая статическая взаимосвязь } \\
\text { Weak linear relationship }\end{array}$ \\
\hline $0,09 \leq r \leq 0,19$ & $\begin{array}{l}\text { Oчень слабая статическая взаимосвязь } \\
\text { Very weak linear relationship }\end{array}$ \\
\hline$r 0$ & $\begin{array}{l}\text { Koppeляции нет (линейной) } \\
\text { No linear relationship }\end{array}$ \\
\hline
\end{tabular}

Результаты вычисления ошибки коэффициента корреляции результатов геотехнического мониторинга по рассматриваемым зданиям приведены в табл. 7.

Оценка достоверности коэффициента корреляции с помощью $t$-критерия Стьюдента приводится в табл. 8.

Статистический корреляционный анализ, примененный к замерам вертикальных перемещений по стенным маркам, показывает следующее. Так как расчетное значение $t$-критерия Стьюдента выше табличного $\left(t_{\text {расч }}>t_{\text {таб. }}\right)$, то можно сделать заключение о том, что величина коэффициента корреляции является значимой, связь существенная и нулевая гипотеза отклоняется. Поскольку (фактическое) во всех случаях выше $t$-табличного, связь между результативным и факторными показателями является надежной, а величина коэффициентов корреляции значимой. Величина коэффициента корреляции считается достоверной, так как не менее чем в 3 раза превышает свою среднюю ошибку. Таким образом, коэффициент корреляции достоверен, что не вызывает необходимости увеличения числа наблюдений.

Таблица 3. Матрица коэффиииента корреляиия для здания по адресу: ул. Большая Садовая, д. 5, стр. 2

Table 3. Matrix of correlation coefficient for the building at Bolshaya Sadovaya street, 5, bld. 2

\begin{tabular}{|c|c|c|c|c|c|c|c|c|c|c|c|c|c|c|c|c|c|c|c|}
\hline $\begin{array}{c}\text { Номера марок } \\
\text { Marks no. }\end{array}$ & 38 & 39 & 40 & 41 & 42 & 43 & 44 & 45 & 46 & 47 & 48 & 49 & 50 & 51 & 52 & 53 & 54 & $52 \mathrm{a}$ & $52 \sigma$ \\
\hline 38 & 1,00 & 0,82 & 0,81 & 0,77 & 0,78 & 0,69 & 0,67 & 0,65 & 0,72 & $-0,28$ & $-0,28$ & \begin{tabular}{|l|l}
0,93 \\
\end{tabular} & 0,68 & $-0,25$ & $-0,26$ & 0,75 & 0,82 & $-0,74$ & $-0,67$ \\
\hline 39 & 0,82 & 1,00 & 0,84 & 0,85 & 0,80 & 0,73 & 0,80 & \begin{tabular}{|l|l|}
0,79 \\
\end{tabular} & 0,45 & \begin{tabular}{|l|l}
$-0,66$ \\
\end{tabular} & $-0,66$ & \begin{tabular}{|l|}
0,92 \\
\end{tabular} & 0,86 & $\mid-0,64$ & $-0,65$ & 0,89 & 0,92 & 0,66 & 0,76 \\
\hline 40 & 0,81 & 0,84 & 1,00 & 0,70 & 0,52 & 0,53 & 0,53 & 0,56 & 0,37 & $-0,48$ & $-0,48$ & \begin{tabular}{|l|l|}
0,90 \\
\end{tabular} & 0,63 & $-0,46$ & $-0,46$ & 0,84 & 0,81 & 0,34 & 0,50 \\
\hline 41 & 0,77 & 0,85 & 0,70 & 1,00 & 0,82 & 0,71 & 0,82 & \begin{tabular}{|l|l|}
0,80 \\
\end{tabular} & 0,38 & $-0,63$ & $-0,63$ & 0,85 & 0,82 & $\mid-0,61$ & $\mid-0,63$ & 0,86 & 0,93 & 0,74 & 0,68 \\
\hline 42 & 0,78 & 0,80 & 0,52 & 0,82 & 1,00 & 0,79 & 0,88 & 0,83 & 0,61 & $-0,51$ & $-0,52$ & 0,77 & 0,79 & $-0,50$ & $-0,52$ & 0,69 & 0,79 & 0,56 & 0,51 \\
\hline 43 & 0,69 & 0,73 & 0,53 & 0,71 & 0,79 & 1,00 & 0,91 & 0,88 & 0,69 & $-0,56$ & $-0,57$ & 0,72 & 0,85 & $-0,56$ & $-0,56$ & 0,55 & 0,78 & 0,30 & 0,22 \\
\hline 44 & 0,67 & 0,80 & 0,53 & 0,82 & 0,88 & 0,91 & 1,00 & 0,94 & 0,56 & $-0,61$ & $-0,63$ & 0,74 & 0,89 & $-0,61$ & $-0,62$ & 0,70 & 0,84 & 0,79 & 0,68 \\
\hline 45 & 0,65 & 0,79 & 0,56 & 0,80 & 0,83 & 0,88 & 0,94 & 1,00 & 0,53 & $-0,72$ & $-0,74$ & 0,75 & 0,85 & $-0,72$ & $-0,73$ & 0,68 & 0,83 & 0,73 & 0,79 \\
\hline 46 & 0,72 & 0,45 & 0,37 & 0,38 & 0,61 & 0,69 & 0,56 & 0,53 & 1,00 & 0,03 & 0,02 & 0,53 & 0,50 & 0,03 & 0,03 & 0,24 & 0,43 & $-0,90$ & $-0,86$ \\
\hline 47 & $-0,28$ & $-0,66$ & $-0,48$ & $-0,63$ & $-0,51$ & $-0,56$ & $-0,61$ & $-0,72$ & 0,03 & 1,00 & 1,00 & $-0,51$ & $-0,65$ & 1,00 & 1,00 & $-0,56$ & $-0,63$ & $-0,76$ & $-0,86$ \\
\hline 48 & $-0,28$ & $-0,66$ & $-0,48$ & $-0,63$ & $-0,52$ & $-0,57$ & $-0,63$ & $-0,74$ & 0,02 & 1,00 & 1,00 & $-0,52$ & $-0,66$ & 1,00 & \begin{tabular}{|l|}
1,00 \\
\end{tabular} & $-0,56$ & \begin{tabular}{|l|}
$-0,64$ \\
\end{tabular} & $-0,77$ & $-0,87$ \\
\hline 49 & 0,93 & 0,92 & 0,90 & 0,85 & 0,77 & 0,72 & 0,74 & 0,75 & 0,53 & $-0,51$ & $-0,52$ & 1,00 & 0,77 & $-0,49$ & $-0,50$ & 0,89 & 0,93 & 0,56 & 0,64 \\
\hline 50 & 0,68 & 0,86 & 0,63 & 0,82 & 0,79 & 0,85 & 0,89 & 0,85 & 0,50 & $-0,65$ & $-0,66$ & 0,77 & 1,00 & $-0,65$ & $-0,66$ & 0,75 & 0,86 & 0,78 & 0,72 \\
\hline 51 & $-0,25$ & $-0,64$ & $-0,46$ & $-0,61$ & $-0,50$ & $-0,56$ & $-0,61$ & $-0,72$ & 0,03 & 1,00 & 1,00 & $-0,49$ & $-0,65$ & 1,00 & 1,00 & $-0,54$ & $-0,62$ & $-0,77$ & $-0,87$ \\
\hline 52 & $-0,26$ & $-0,65$ & $-0,46$ & $-0,63$ & $-0,52$ & $-0,56$ & $-0,62$ & $-0,73$ & 0,03 & 1,00 & 1,00 & $-0,50$ & $-0,66$ & 1,00 & \begin{tabular}{|l|}
1,00 \\
\end{tabular} & $-0,55$ & $-0,63$ & $-0,78$ & $-0,87$ \\
\hline 53 & 0,75 & 0,89 & 0,84 & 0,86 & 0,69 & 0,55 & 0,70 & 0,68 & 0,24 & $-0,56$ & $-0,56$ & 0,89 & 0,75 & $-0,54$ & $-0,55$ & 1,00 & 0,91 & 0,93 & 0,79 \\
\hline 54 & 0,82 & 0,92 & 0,81 & 0,93 & 0,79 & 0,78 & 0,84 & 0,83 & 0,43 & $-0,63$ & $-0,64$ & 0,93 & 0,86 & $-0,62$ & $-0,63$ & 0,91 & 1,00 & 0,91 & 0,84 \\
\hline $52 \mathrm{a}$ & $-0,74$ & 0,66 & 0,34 & 0,74 & 0,56 & 0,30 & 0,79 & 0,73 & $-0,90$ & $-0,76$ & $-0,77$ & 0,56 & 0,78 & $-0,77$ & $-0,77$ & 0,93 & 0,91 & 1,00 & 0,90 \\
\hline 526 & $-0,67$ & 0,76 & 0,50 & 0,68 & 0,51 & 0,22 & 0,68 & 0,79 & $-0,86$ & $-0,86$ & $-0,87$ & 0,64 & 0,72 & $-0,87$ & $-0,87$ & 0,79 & 0,84 & 0,90 & 1,00 \\
\hline
\end{tabular}


Известия Томского политехнического университета. Инжиниринг георесурсов. 2019. Т. 330. № 8. 190-204

Кулешов А.П., Пендин В.В. К вопросу обработки результатов геотехнического мониторинга за осадками сооружений

Таблица 4. Матрица коэффициента корреляция для здания по адресу: ул. Гашека, д. 12, стр. 2

Table 4. $\quad$ Matrix of correlation coefficient for the building at Gashek street, 12, bld. 2

\begin{tabular}{|c|c|c|c|c|c|c|c|c|c|c|c|c|c|c|c|c|c|c|}
\hline $\begin{array}{l}\text { Номера марок } \\
\text { Mark no. }\end{array}$ & 64 & 65 & 66 & 67 & 68 & 69 & 70 & 71 & 72 & 73 & 74 & 75 & 76 & 77 & 78 & 79 & 80 & 81 \\
\hline 64 & 1,00 & 0,93 & 0,93 & 0,82 & 0,93 & 0,96 & 0,94 & 0,89 & 0,86 & 0,93 & 0,91 & 0,91 & 0,95 & 0,79 & 0,93 & 0,91 & 0,95 & 0,73 \\
\hline 65 & 0,93 & 1,00 & 0,95 & 0,89 & 0,92 & 0,95 & 0,93 & 0,93 & 0,90 & 0,97 & 0,91 & 0,95 & 0,94 & 0,88 & 0,92 & 0,88 & 0,90 & 0,67 \\
\hline 66 & 0,93 & 0,95 & 1,00 & 0,91 & 0,92 & 0,95 & 0,91 & 0,91 & 0,86 & 0,95 & 0,91 & 0,91 & 0,96 & 0,88 & 0,87 & 0,95 & 0,88 & 0,74 \\
\hline 67 & 0,82 & 0,89 & 0,91 & 1,00 & 0,79 & 0,89 & 0,73 & 0,89 & 0,77 & 0,83 & 0,72 & 0,86 & 0,87 & 0,78 & 0,75 & 0,92 & 0,80 & 0,79 \\
\hline 68 & 0,93 & 0,92 & 0,92 & 0,79 & 1,00 & 0,92 & 0,94 & 0,90 & 0,81 & 0,96 & 0,95 & 0,91 & 0,94 & 0,86 & 0,93 & 0,85 & 0,90 & 0,61 \\
\hline 69 & 0,96 & 0,95 & 0,95 & 0,89 & 0,92 & 1,00 & 0,90 & 0,91 & 0,87 & 0,93 & 0,87 & 0,92 & 0,95 & 0,79 & 0,92 & 0,91 & 0,96 & 0,74 \\
\hline 70 & 0,94 & 0,93 & 0,91 & 0,73 & 0,94 & 0,90 & 1,00 & 0,88 & 0,87 & 0,96 & 0,96 & 0,90 & 0,93 & 0,86 & 0,94 & 0,82 & 0,89 & 0,56 \\
\hline 71 & 0,89 & 0,93 & 0,91 & 0,89 & 0,90 & 0,91 & 0,88 & 1,00 & 0,86 & 0,93 & 0,86 & 0,94 & 0,91 & 0,82 & 0,89 & 0,86 & 0,84 & 0,59 \\
\hline 72 & 0,86 & 0,90 & 0,86 & 0,77 & 0,81 & 0,87 & 0,87 & 0,86 & 1,00 & 0,89 & 0,82 & 0,93 & 0,91 & 0,71 & 0,90 & 0,73 & 0,87 & 0,55 \\
\hline 73 & 0,93 & 0,97 & 0,95 & 0,83 & 0,96 & 0,93 & 0,96 & 0,93 & 0,89 & 1,00 & 0,96 & 0,94 & 0,95 & 0,87 & 0,95 & 0,87 & 0,89 & 0,58 \\
\hline 74 & 0,91 & 0,91 & 0,91 & 0,72 & 0,95 & 0,87 & 0,96 & 0,86 & 0,82 & 0,96 & 1,00 & 0,86 & 0,91 & 0,84 & 0,91 & 0,82 & 0,83 & 0,50 \\
\hline 75 & 0,91 & 0,95 & 0,91 & 0,86 & 0,91 & 0,92 & 0,90 & 0,94 & 0,93 & 0,94 & 0,86 & 1,00 & 0,96 & 0,81 & 0,94 & 0,84 & 0,92 & 0,62 \\
\hline 76 & 0,95 & 0,94 & 0,96 & 0,87 & 0,94 & 0,95 & 0,93 & 0,91 & 0,91 & 0,95 & 0,91 & 0,96 & 1,00 & 0,84 & 0,92 & 0,90 & 0,94 & 0,70 \\
\hline 77 & 0,79 & 0,88 & 0,88 & 0,78 & 0,86 & 0,79 & 0,86 & 0,82 & 0,71 & 0,87 & 0,84 & 0,81 & 0,84 & 1,00 & 0,76 & 0,81 & 0,74 & 0,64 \\
\hline 78 & 0,93 & 0,92 & 0,87 & 0,75 & 0,93 & 0,92 & 0,94 & 0,89 & 0,90 & 0,95 & 0,91 & 0,94 & 0,92 & 0,76 & 1,00 & 0,79 & 0,92 & 0,53 \\
\hline 79 & 0,91 & 0,88 & 0,95 & 0,92 & 0,85 & 0,91 & 0,82 & 0,86 & 0,73 & 0,87 & 0,82 & 0,84 & 0,90 & 0,81 & 0,79 & 1,00 & 0,83 & 0,81 \\
\hline 80 & 0,95 & 0,90 & 0,88 & 0,80 & 0,90 & 0,96 & 0,89 & 0,84 & 0,87 & 0,89 & 0,83 & 0,92 & 0,94 & 0,74 & 0,92 & 0,83 & 1,0 & 0,71 \\
\hline 81 & 0,73 & 0,67 & 0,74 & 0,79 & 0,61 & 0,74 & 0,56 & 0,59 & 0,55 & 0,58 & 0,50 & 0,62 & 0,70 & 0,64 & 0,53 & 0,81 & 0,71 & 1,00 \\
\hline
\end{tabular}

Таблица 5. Матрица коэффициента корреляиия для здания по адресу: ул. Большая Садовая, д. 5, стр. 1

Table 5. Correlation coefficient matrix for the building at Bolshaya Sadovaya street, 5, bld. 1

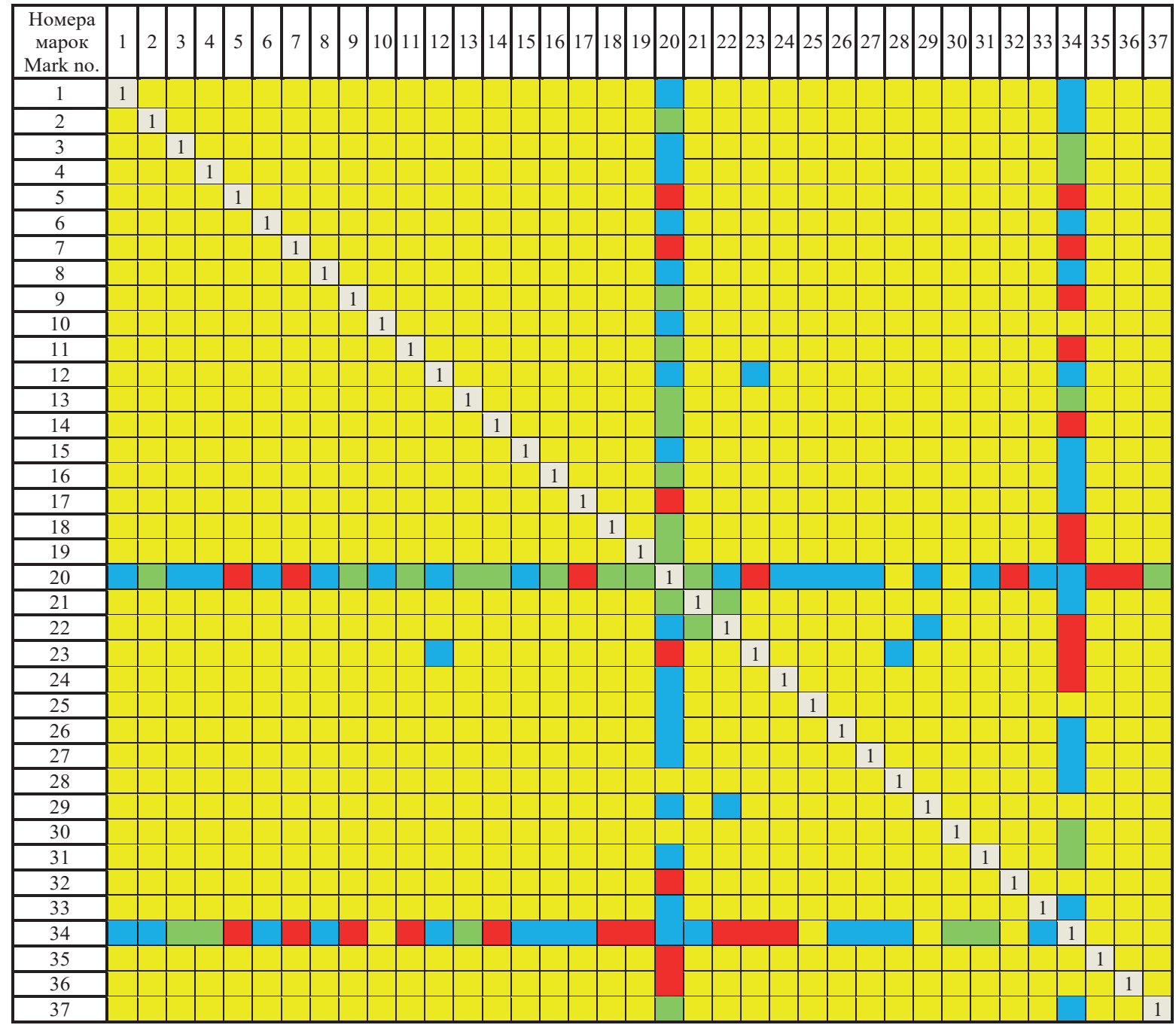

Значение коэффициента корреляции

$R=0,20 \ldots 0,99$

$R=0,00 \ldots 0,19$

$R=-0,01 \ldots-0,09$

$R=-0,10 \ldots-0,90$ 
Таблица 6. Матрица коэффициента корреляция для здания по адресу: ул. Гашека, ә. 12, стр. 8

Table 6. $\quad$ Matrix of correlation coefficient for the building at Gashek street, 12, bld. 8

\begin{tabular}{|c|c|c|c|c|c|c|c|c|c|c|c|c|c|c|}
\hline $\begin{array}{l}\text { Номера марок } \\
\text { Mark no. }\end{array}$ & 82 & 83 & 84 & 85 & 86 & 87 & 88 & 89 & 90 & 91 & 92 & 93 & 94 & 95 \\
\hline 82 & 1,00 & 0,80 & 0,87 & 0,60 & 0,82 & 0,92 & 0,62 & 0,68 & 0,18 & 0,92 & 0,90 & 0,74 & 0,87 & 0,92 \\
\hline 83 & 0,80 & 1,00 & 0,71 & 0,74 & 0,80 & 0,79 & 0,77 & 0,80 & 0,52 & 0,83 & 0,80 & 0,86 & 0,80 & 0,80 \\
\hline 85 & 0,60 & 0,74 & 0,68 & 1,00 & 0,83 & 0,62 & 0,93 & 0,80 & 0,78 & 0,77 & 0,76 & 0,93 & 0,72 & 0,65 \\
\hline 86 & 0,82 & 0,80 & 0,92 & 0,83 & 1,00 & 0,80 & 0,84 & 0,93 & 0,51 & 0,93 & 0,92 & 0,88 & 0,76 & 0,77 \\
\hline 89 & 0,68 & 0,80 & 0,77 & 0,80 & 0,93 & 0,64 & 0,85 & 1,00 & 0,64 & 0,79 & 0,80 & 0,87 & 0,65 & 0,61 \\
\hline 90 & 0,18 & 0,52 & 0,26 & 0,78 & 0,51 & 0,15 & 0,76 & 0,64 & 1,00 & 0,34 & 0,34 & 0,68 & 0,36 & 0,20 \\
\hline 91 & 0,92 & 0,83 & 0,95 & 0,77 & 0,93 & 0,95 & 0,79 & 0,79 & 0,34 & 1,00 & 0,97 & 0,86 & 0,90 & 0,94 \\
\hline 92 & 0,90 & 0,80 & 0,94 & 0,76 & 0,92 & 0,94 & 0,77 & 0,80 & 0,34 & 0,97 & 1,00 & 0,86 & 0,91 & 0,91 \\
\hline 93 & 0,74 & 0,86 & 0,75 & 0,93 & 0,88 & 0,78 & 0,91 & 0,87 & 0,68 & 0,86 & 0,86 & 1,00 & 0,85 & 0,77 \\
\hline
\end{tabular}

таблица 7. Значение средней ошибки коэффициента корреляции Table 7. Value of the average error of the correlation coefficient

\begin{tabular}{|c|c|c|c|}
\hline \multicolumn{4}{|c|}{$\begin{array}{l}\text { Значение средней ошибки коэффициента корреляции для зданий } \\
\text { по адресам } \\
\text { Value of the average error of the correlation coefficient for buildings at }\end{array}$} \\
\hline ул. Гашека, & ул. Гашека, & ул. Большая $\mathrm{Ca}-$ & ул. Большая $\mathrm{Ca}-$ \\
\hline $\begin{array}{c}\text { Gashek street, } \\
12, \text { bld. } 2\end{array}$ & $\begin{array}{c}\text { Gashek street, } \\
12 \text {, bld. } 8\end{array}$ & $\begin{array}{l}\text { Bolshaya Sadova- } \\
\text { ya street, } 5 \text {, bld. } 1\end{array}$ & $\begin{array}{c}\text { Bolshaya Sadovaya } \\
\text { street, } 5 \text {, bld. } 2\end{array}$ \\
\hline 0,12 & 0,18 & 0,13 & 0,23 \\
\hline
\end{tabular}

Таблица 8. Оценка достоверности коэффициента корреляиии Table 8. Evaluation of the correlation coefficient reliability

\begin{tabular}{|c|c|c|c|}
\hline \multicolumn{4}{|c|}{ Значение $t$-критерия Стьюдента/Value of Student's $t$-test } \\
\hline \multicolumn{4}{|c|}{ Здание по адресу/Building at } \\
\hline ул. Гашека, & ул. Гашека, & ул. Большая Са- & ул. Большая Садо- \\
д. 12, стр. 2 & д. 12, стр. 8 & довая, д. 5, стр. 1 & вая, д. 5, стр. 2 \\
Gashek street, & Gashek street, & Bolshaya Sadovaya & Bolshaya Sadovaya \\
12, bld. 2 & 12, bld. 8 & street, 5, bld. 1 & street, 5, bld. 2 \\
\hline 8,30 & 5,70 & 7,96 & 4,36 \\
\hline
\end{tabular}

Наличие высокозначимой (сильной) $R=0,99 \ldots 0,70$, значимой (средней) $R=0,50 \ldots 0,69$ и слабой $R=0,20 \ldots 0,49$ прямой корреляции между перемещениями марок говорит о едином характере перемещения и, следовательно, об одинаковой «работе» элементов конструкции, на которых установлены марки.

Наличие высокозначимой (сильной) $R=0,99 \ldots 0,70$, значимой (средней) $R=0,50 \ldots 0,69$ и слабой $R=0,20 \ldots 0,49$ обратной корреляции между перемещениями марок свидетельствует о противоположном характере перемещения марок, а значит о перекосе конструкции, что является признаком напряженного состояния конструкции и предвестником развития деформаций.

Коэффициент корреляции близкий к $0,00 \ldots 0,19$ (связи нет) свидетельствует об отсутствии статистической взаимосвязи между коррелируемыми величинами, а значит о независимой друг от друга работе элементов конструкций, на которых расположены марки.

Результаты проведенного корреляционного анализа представлены в виде матрицы значений (табл. 3-6) и карты взаимосвязи осадок различных марок с выделением зон риска (рис. 8). Расчёты показали следующее:

- Значимая (средняя), высокозначимая (сильняя) и слабая корреляция с $R=0,20 \ldots 0,99$ присутствует между всеми марками, расположенными на здании по адресу: ул. Гашека д. 12 стр. 2 (марки № 64-81) и отдельных марок по адресу: ул. Гашека, д. 12 стр. 8 (марки № 82-89, 91-94), ул. Б. Садовая, д. 5, стр. 1 (марки № 1-19; 24-31, 33), ул. Б. Садовая, д. 5, стр. 2 (марки № 38-46).

- По некоторым маркам здания по адресу: ул. Гашека, д. 12, стр. 8 (марки № 90, 95) корреляционный анализ показал незначимые величины коэффициента корреляции $R=0,00 \ldots 0,19$, что говорит о независимой работе разных строительных конструкций или свидетельствует 0 независимой друг от друга работе элементов конструкции.

- Отрицательные значения $R$, незначительные по величине, получились между марками № $21,22,30,36,37$ для здания по адресу: ул. Б. Садовая, д. 5 , стр. 1.

- Расчет коэффициента корреляции между перемещениями марок № $20,23,32,34,35$ для здания по адресу: ул. Б. Садовая, д. 5 , стр. 1 и № 47-54 - ул. Б. Садовая, д. 5, стр. 2 показал значение $R=-0,10 \ldots-0,90$, что говорит о наличии достаточно тесной взаимосвязи в движении марок, а поскольку марки установлены на одном конструктивном элементе, то и о возможных деформациях, «зонах риска».

Анализ значений коэффициента корреляции (таблицы № 3-6) подтвердил выявленную неравномерность перемещения ряда марок по принципу «качелей». Это относится к маркам № $20,23,32,34,35$ $(R=-0,10 \ldots-0,90)$ и марки № $1-19 ; 24-31,33$ $(R=0,2 \ldots 0,99)$ для здания по адресу: ул. Б. Садовая, д. 5 , стр. 1 ; № $47-54(R=-0,10 \ldots-0,90)$ и марки № 38-46 $(R=0,20 . . .0,99)$ - ул. Б. Садовая, д. 5, стр. 2.

Таким образом, участки конструкций, на которых расположены вышеуказанные марки, могут 
считаться вероятными зонами риска по развитию деформаций. Полученные результаты подтверждают предположения о напряженном состоянии конструкции и вероятной (возможной) блоковой структуре строения внутренних и наружных стен для зданий по адресу: ул. Б. Садовая, д. 5, стр. 1, 2 . Между перемещениями марок № 21, 22, 30, 36, 37 и № $20,23,32,34,35$ коэффициент корреляции имеет отрицательную величину $R_{21,22,30,36,37}=-0,01$ и $R_{20,23,32,34,35}=-0,29$ соответственно для здания по адресу: ул. Б. Садовая, д. 5 стр. 1, что свидетельствует об обратной корреляционной зависимости и отсутствии статистической взаимосвязи между коррелируемыми величинами, а значит, о независимой работе конструктивных элементов. Корреляционный анализ подтвердил качественные выводы, сделанные ранее, о закономерной неравномерности перемещений марок разных конструктивных элементов и выявил зоны, где вероятнее всего могут произойти деформации [26]. Полученные результаты проведенного корреляционного анализа свидетельствуют об эффективности его применения при анализе результатов наблюдений за вертикальными перемещениями конструкций. Неравномерное перемещение марок после проведенных работ - свидетельство неравномерной осад- ки и развития разрывной деформации между разновременными конструкциями. Можно сказать, что здания по адресу: ул. Б. Садовая, д. 5, стр. 1, 2, находятся в переходном режиме функционирования, состоянии адаптации системы к новым условиям. Процесс адаптации идет, отмечаются внешние незначительные нарушения, зафиксированные в ходе всего периода мониторинга (осадки значительные). Влияние колебаний уровня грунтовых вод, их взвешивающего действия на фундаменты пока не подтверждается.

На устойчивость конструкций в данное время более всего могут влиять: значительная неоднородность грунтов, начало нового строительства и эволюционные процессы в основании. Зафиксированные деформации к концу инструментальных наблюдений стабилизировались, и отпала необходимость в дальнейшем проведении работ за наблюдением перемещений марок [27].

Оперативный мониторинг позволил выявить основные этапы адаптации сооружения к происходящим взаимодействиям на основании изменения измеряемых параметров (в данном случае величины перемещения стенных марок) и их контроля (были выявлены «зоны риска»- участки, где конструкции находятся в напряженном состоянии).

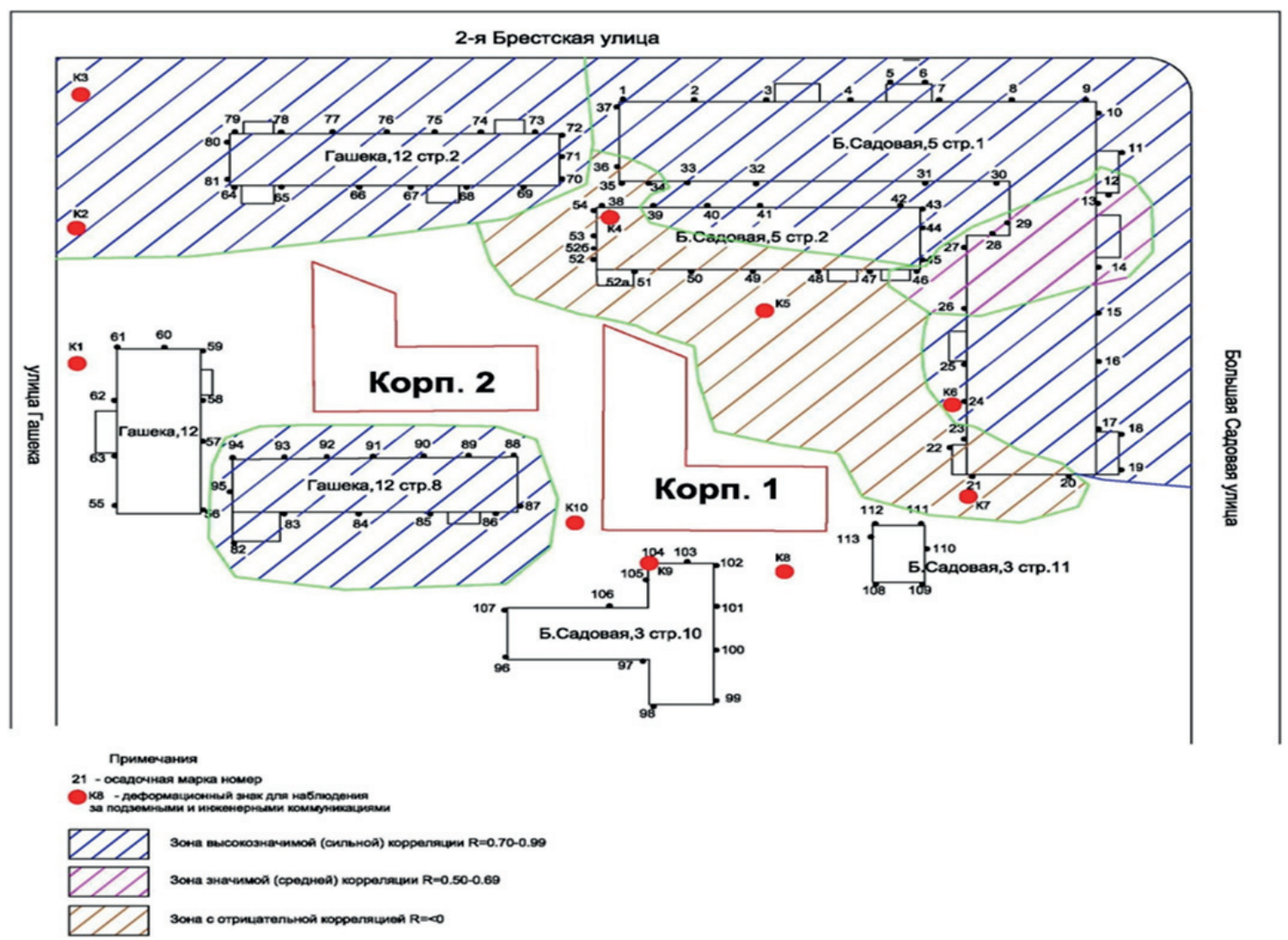

Pис. 8. Карта взаимосвязи осадок различных марок в зоне окружающей застройки многофункиионального делового иентра с подзелной автостоянкой по адресу: г. Москва, ул. Большая Садовая, д. 5, стр. 1, 2; ул. 2-я Брестскал, д. 1, стр. 1; ул. Гашека, вл. 12 часть стр. 1 (подъезды 1-4), стр. 5-7

Fig. 8. Map of relationship of sediment of different brands in the area of the surrounding development of a multifunctional business center with underground parking in Moscow, Bolshaya Sadovaya street, 5, bld.1, 2; 2-ya Brestskaya street, 1, bld. 1; Gashek street, 12 part, bld. 1 (entrances 1-4), blds. 5-7 


\section{Заключение}

Наличие системы мониторинга для элементарных ПТС, составных частей ЛПТС, до, вовремя и после управляемых техногенных взаимодействий приводит к корректной оценке эффективности проведенных работ и делает прогнозируемой стабильность работы сооружений в дальнейшем [28].

Результаты работы, предлагаемый алгоритм концепции, может быть использован в качестве одной из составляющих общей концепции устойчивости зданий и сооружений. Применение алгоритма «Статистического корреляционного анализа» к локальным ПТС позволяет обобщить разновозрастный фактический материал, составить актуализированные модели строения сферы взаимодействия, что дает возможность скорректировать и оптимизировать управляющие мероприятия, а также проектные решения.

Полученные значения коэффициента корреляции $(R)$ могут служить индикатором напряженности конструкций или конструкции, что дает возможность оконтурить зоны повышенной потенциальной опасности, выявить зоны риска.

Применительно к сложным, потенциально опасным объектам использование анализа риска осуществляется с целью получения возможности принятия научно обоснованных решений по уменьше-

\section{СПИСОК ЛИТЕРАТУРЫ}

1. Абрамова Т.Т. Экомониторинг подземного археологического музея г. Москвы // Природные условия строительства и сохранения храмов Православной Руси. Московская Патриархия Троице-Сергиева Лавра: Сборник трудов 6-го Международного научно-практического симпозиума. - Сергиев Посад, 2016. C. $117-130$.

2. ГОСТ Р 56198-2014 Мониторинг технического состояния объектов культурного наследия. Недвижимые памятники. 0бщие требования. - М.: Стандартинформ, 2014. - 28 с.

3. ГОСТ 24846-2012 Грунты. Методы измерений деформаций оснований зданий и сооружений. - М.: Стандартинформ, 2014 . $18 \mathrm{c.}$

4. ГОСТ 31937-2011 Здания и сооружения. Правила обследования и мониторинга технического состояния. - М.: Стандартинформ, 2014. $-54 \mathrm{c}$.

5. Никифоров А.А., Дмитриев В.В. Исторические фундаменты как элемент историко- культурного наследия // Природные условия строительства и сохранения храмов Православной Руси. Московская Патриархия Троице-Сергиева Лавра: Сб. трудов 6-го Международного научно-практического симпозиума. - Сергиев Посад, 2016. - С. 91-97.

6. Подборская В.О., Невечеря В.В. Обобщение результатов режимных наблюдений за процессом криогенного пучения грунтов на территории Кирилло-Белозерского музея - заповедника // Известия высших учебных заведений. Геология и разведка. 2016. - № 6. - С. 60-66.

7. Пендин В.В. Комплексный количественный анализ информации в инженерной геологии. - М.: КДУ,2009. - 350 с.

8. Системы мониторинга локальных исторических природно-технических систем (ИПТС) - как основа мероприятий по долговременному сохранению объектов культуры / В.В. Пендин, Л.В. Заботкина, В.О. Подборская, В.В. Невечеря // Геоэкология. -2016 . - № 1. - С. 81-93. нию негативных воздействий инженерно-геологических процессов на основе количественных оценок.

Проведение геотехнического мониторинга существующей застройки, попадающей в зону влияния нового строительства, обусловлено необходимостью обеспечения своевременного информирования о выявленных отклонениях контролируемых параметров (в том числе тенденций их изменений, превышающие ожидаемые) от проектных значений.

Данная схема анализа мониторинга призвана обеспечить решение ряда задач: создание системы накопления и обработки информации, получаемой в результате функционирования режимных сетей; организация блока, ответственного за выдачу прогнозных математических моделей, разработка сценариев для принятия управляющих рекомендаций по обеспечению надежного функционирования сооружения.

Использование метода статистического моделирования в результате проявления негативных инженерно-геологических процессов позволяет предварительно спрогнозировать дальнейшее изменение состояния ПТС и ее теоретический срок функционирования в пределах области допустимых состояний, дает возможность получить систему критериев безопасности.

9. СП 305.1325800.2017. Здания и сооружения. Правила проведения геотехнического мониторинга при строительстве. - М.: Стандартинформ, 2017. - 69 с.

10. СП 22.13330.2016. Основания зданий и сооружений. - М.: Стандартинформ, 2016. - 69 с.

11. ТСН 50-304-2001 г. Москвы (МГСН 2.07-01) Основания, фундаменты и подземные сооружения. - М.: ГУП города Москвы «НИАЦ», 2003. - 41 с.

12. Пашкин Е.М., Бессонов Е.Б. Диагностика деформаций памятников архитектуры. - М.: Стройиздат, 1984. - 151 с.

13. Пургина Д.В., Строкова Л.А., Кузеванов К.И. Моделирование гидрогеологических условий для обоснования противооползневых мероприятий на участке набережной реки Камы в городе Пермь // Известия Томского политехнического университета. Инжиниринг георесурсов. - 2016. - Т. 327. - № 1. C. $116-127$.

14. Строкова Л.А., Епифанова Е.А., Коржнева Т.Г. Численный анализ поведения основания опоры моста на старой железнодорожной линии // Известия Томского политехнического университета. Инжиниринг георесурсов. - 2017. - Т. 328. - № 5. C. $125-139$.

15. Улицкий В.М., Шашкин А.Г. Геотехническое сопровождение реконструкции городов. - М.: Изд-во АСВ, 1999. - 327 с.

16. Решение задач геодезического мониторинга колонн и ферм покрытия / Е.Н. Хмырова, О.Г. Бесимбаева, Е.А. Олейникова, P.В. Синяк // Кадастр недвижимости и мониторинг природных ресурсов: Труды Международной научно-технической интернет-конференции. - Тула, 2016. - Т. 1. - С. 581-586.

17. Brakorenko N.N. Impact of oil on groundwater chemical composition // IOP Conference Series: Earth and Environmental Science. 2015. - № 27. $-6 \mathrm{p}$.

18. Katzenbach R., Schmitt A., Ramm K. Basic principles of design and monitoring of high-rise buildings in Frankfurt-on-Main. Practical cases // Rekomstr. Gorodov Geotekh. Stroit. - 2005. № 9. - P. 80-99. 
19. Mayne P.W. Keynote lecture: in-situ geocharacterization of soils in the year 2016 and beyond // Advances in Soil Mechanics: Geotechnical Synergy: Proc. 15 PCSMGE. -Buenos Aires, 2015. Amsterdam: IOS Press, 2015. - V. 5. - P. 139-161.

20. Hiller Bernd. Technology of geodetic deformation monitoring-experience use // Safety of construction and operation of facilities: Open town-planning forum, the session. - Novosibirsk, 2010. P. 111-115.

21. Pythoud S.R. Determination experimentale des parametres de securite desproduits chimiques // Chimia. - 2003. - V. 57. № 12. - P. 766-769.

22. Strokova L.A., Ermolaeva A.V., Golubeva V.V. The Investigation of Dangerous Geological Processes Resulting In Land Subsidence While Designing the Main Gas Pipeline in South Yakutia // IOP Conference Series: Earth and Environmental Science. - 2016. V. $43 .-6 \mathrm{p}$.

23. Strokova L.A. Modeling of tunneling induced ground surface mo vement / Scientific and Technical Challenges in the Well Drilling Progress // IOP Conference Series: Earth and Environmental Science. - 2015. - № 24. $-6 \mathrm{p}$.
24. Yang H., Xu X., Neumann I. Laser scanning based updating of a finite element model for structural health monitoring // IEEE Sensor. - 2016. - V. 7. - P. 2100-2104.

25. Terrestrial Laser Scanning Technology for Deformation Monitoring and Sur face Modeling of Arch Structures / H. Yang, M. Omidalizarandi, X. Xu, I.I. Neumann // Composite Structures. - 2016. - V. 149. - P. 93-105.

26. Yardim Y., Mustafaraj E. Effects of soil settlement and deformed geometry on a historical structure // Natural hazards and Earth System Sciences. - 2015. - V. 15. - P. 1051-1059.

27. Terrestrial laser scanner for monitoring the deformations and the damages of buildings / G. Vacca, F. Mistretta, F. Stochino, A. Dessi // International Archives of the Photogrammetry, Remote Sensing \& Spatial Information Sciences. - 2016. - V. 41. Iss. B5. - P. 453-460.

28. Кулешов А.П., Пендин В.В. Влияние методики определения свойств грунтов в численных расчетах деформаций // Известия Томского политехнического университета. Инжиниринг георесурсов. - 2017. - Т. 328. - № 12. - С. 63-74.

Поступила 10.07.2018 г.

\section{Информация об авторах}

Кулешов А.П., аспирант кафедры инженерной геологии Российского государственного геологоразведочного университета им. Серго Орджоникидзе.

Пендин В.В., доктор геолого-минералогических наук, профессор, заведующий кафедрой инженерной геологии Российского государственного геологоразведочного университета им. Серго Орджоникидзе. 


\title{
ON THE ISSUE OF PROCESSING THE RESULTS OF GEOTECHNICAL MONITORING OF STRUCTURE SETTLEMENT
}

\author{
Alexander P. Kuleshov', \\ kuleshov@inzhgeos.ru \\ Vadim V. Pendin', \\ pendin@yandex.ru
1 Sergo Ordzhonikidze Russian State Geological Prospecting University, 23, Miklukho-Maklay street, Moscow, 117997, Russia.

The relevance of the work is caused by preservation of the existing building, which is in the zone of influence of new construction. After identification of engineering-geological processes affecting adversely the conditions of operation of the facility, and determination of parameters on which the development of such processes depend, there is a need to assess the level of risk. Recently, the correlation and regression analysis of data regime observations, based on the probability-statistical group of methods - naturally random nature of the development of processes in time and space, is the most frequently used one.

The main aim of the research is the statistical analysis of the characteristics of building deformation values under the influence of new construction, finding and description of the relationship between sedimentary marks and deformation signs located on the buildings, evaluation of operation mode of elementary natural and technical systems in complex engineering-geological conditions, analysis of accumulated engineering-geological information on the object, including the results of pre-construction surveys.

Methods: analysis of regime observations with the help of autocorrelation function, comparison of the results with the data of natural long-term observations, representation of the object of study in the form of a complex system consisting of a set of elements between which there are relations and interactions, establishment of a set of dangers, allocation of risk zones for a certain object in the form of possible losses in time, assessment of the vulnerability of affected objects from each of the identified processes, the forecast of the development of technopriodic hazards in space, deformation shooting.

Results. One of the most important components of ensuring reliable and safe operation of any facility is a monitoring system. On the basis of the data obtained during the implementation of lithomonitoring, the system state is monitored by comparing the values of the observed indicators with the standard system of criteria; the management solutions are developed to optimize its operation. Analysis of all the collected materials, as well as the results of diagnostics of the lithotechnical system at the current time, allows identifying the paragenesis of engineering-geological processes that determine the possibility of developing extreme situations that pose a threat to the safe operation of the facility. It is advisable to build maps of the differences that reflect changes in the properties of the interaction of the technical object and the geological body and determine the direction of further development of the state of the system.

\section{Key words:}

Geotechnical monitoring, observation system, correlation analysis, soil, stress-strain state,

deformation process, settlement of structures, regime observations.

\section{REFERENCES}

1. Abramova T.T. Ekomonitoring podzemnogo arkhejlogicheskogo muzeya g. Moskvy [Ecomonitoring of the underground archaeological Museum of Moscow]. Prirodnye usloviya stroitelstva $i$ sokhraneniya khramov Pravoslavnoy Rusi. Moskovskaya Patriarkhiya Troitse-Sergieva Lavra. Sbornik trudov 6-go Mezhdunarodnogo nauchno-prakticheskogo simpoziuma [Natural conditions of construction and preservation of churches of Orthodox Russia. Moscow Patriarchate of the Trinity-Sergius Lavra. Proceedings of the $6^{\text {th }}$ International scientific and practical Symposium]. Sergiev Posad, 2016. pp. 117-130.

2. GOST R 56198-2014. Monitoring tekhnicheskogo sostoyaniya obektov kulturnogo naslediya. Nedvizhimye pamyatniki. Obshchie trebovaniya [State standard of Russia 56198-2014. Monitoring of technical state of the cultural heritage objects. Immovable monuments. General requirements]. Moscow, Standartinform Publ., 2014. $28 \mathrm{p}$.

3. GOST 24846-2012 Grunty. Metody izmereny deformatsy osnovany zdany $i$ sooruzheny [State standard of Russia 24846-2012 Soils. Methods of measuring the strains of structure and building bases]. Moscow, Standartinform Publ., 2014. 18 p

4. GOST 31937-2011 Zdaniya i sooruzheniya. Pravila obsledovaniya $i$ monitoring tekhnicheskogo sostoyaniya [State standard of Russia 31937-2011. Buildings and constructions. Rules of inspection and monitoring of the technical condition]. Moscow, Standartinform Publ., 2014. 54 p.
5. Nikiforov A.A., Dmitriev V.V. Istoricheskie fundamenty kaka elemet istoriko-kulturnogo naslediya [The historical foundations as an element of historical and cultural heritage]. Prirodnye usloviya stroitelstva i sokhraneniya khramov Pravoslavnoy Rusi. Moskovskaya Patriarkhiya Troitse-Sergieva Lavra: Sbornik trudov 6-go Mezhdunarodnogo nauchno-prakticheskogo simpoziuma [Proc. papers of 6 -th International scientific-practical Symposium. The Natural conditions of the construction and preservation of the churches of Orthodox Russia]. Sergiev Posad, 2016. pp. 91-97.

6. Podborskaya V.0., Nevicare V. V. Generalization of the results of monitoring the process of cryogenic heaving of soils on the territory of the Kirillo-Belozersky museum - reserve. Proceedings of higher educational institutions. Geology and exploration, 2016, no. 6, pp. 60-66. In Rus.

7. Pendin V.V. Kompleksny kolichestvenny analiz informatsii $v$ inzhenernoy geologii [Complex quantitative analysis of information in engineering Geology]. Moscow, KDU Publ., 2009. 350 p.

8. Pendin V.V., Zabotkina L.V., Podborskaya V.O., Nevicherya V.V. Monitoring System for local historical natural-technical systems (IPTS) as a framework for long-term preservation of objects of culture. Geoecology, 2016, no. 1, pp. 81-93. In Rus.

9. SP 305.1325800.2017. Zdaniya i sooruzheniya. Pravila povedeniya geotekhnicheskogo monitoring pri stroitelstve [Code of rules 305.1325800 .20 . Buildings and structures. The rules of geotechnical monitoring under construction]. Moscow, Standartinform Publ., 2017. 69 p. 
10. SP 22.13330.2016 Osnovaniya zdaniy i sooruzheniy [Code of rules 22.13330.2016. Soil bases of buildings and structures]. Moscow, Standartinform Publ., 2016. 69 p.

11. TSN 50-304-2001 Moscow (MGSN 2.07-01). Osnovaniya, fundamenty i podzemnye sooruzheniya [The system of normative documents in construction Moscow city building codes 50-304-2001. The bases, foundations and underground structures]. Moscow, GUP goroda Moskvy «NIATS», 2003. $41 \mathrm{p}$.

12. Pashkin E.M., Bessonov E.B. Diagnostika deformatsiy pamyatnikov arkhitektury [Diagnostics of deformations of architectural monuments]. Moscow, Stroyizdat Publ., 1984. 151 p.

13. Purgina D.V., Strokova L.A., Kuzevanov K.I. Modeling hydrogeological conditions for antilandslide measures justification on the plot of the Kama river embankment in Perm. Bulletin of the Tomsk Polytechnic University. Geo Assets Engineering, 2016, vol. 327 , no. 1, pp. 116-127. In Rus.

14. Strokova L.A., Epifanova E.A., Korzhneva T.G. Numerical analysis of bridge foundation behaviour on the old railway line. Bul letin of the Tomsk Polytechnic University. Geo Assets Engineering, 2017, vol. 328, no. 5, pp. 125-139. In Rus.

15. Ulitsky B.M., Shashkin A.G. Geotekhnicheskoe soprovozhdenie rekonstruktsii gorodov [Geotechnical support urban renewal]. Moscow, publishing DIA, 1999. $327 \mathrm{p}$.

16. Khmyrova E.N., Besembaeva 0.G., Oleinikova E.A., Sinyak R.V. Reshenie zadach geodezicheskogo monitoring kolonn i ferm pokrytiya [The decision of the task of geodetic monitoring of $\mathrm{co}^{-}$ lumns and girders of the covering]. Kadastr nedvizhimosti i monitoring prirodnykh resursov. Trudy Mezhdunarodnoy nauchnotekhnicheskoy internet-konferentsii [Kadistr real estate and monitoring of natural resources. Proceedings of the International scientific and technical Internet-conference]. Tula, 2016. Vol. 1, pp. 581-586.

17. Brakorenko N.N. Impact of oil on groundwater chemical composition. IOP Conference Series: Earth and Environmental Science, 2015, no. 27, 6 p.

18. Katzenbach R., Schmitt A., Ramm K. Basic principles of design and monitoring of high-rise buildings in Frankfurt-on- Main. Practical cases. Rekomstr. Gorodov Geotekh. Stroit., 2005, no. 9, pp. 80-99.
19. Mayne P.W. Keynote lecture: in-situ geocharacterization of soils in the year 2016 and beyond. Advances in Soil Mechanics: Geotechnical Synergy: Proc. 15 PCSMGE. Buenos Aires, 2015. Amsterdam, IOS Press, 2015. Vol. 5, pp. 139-161.

20. Hiller Bernd. Technology of geodetic deformation monitoring-experience use. Open town-planning forum, the session. Safety of construction and operation of facilities. Novosibirsk, 2010. pp. 111-115.

21. Pythoud S.R. Determination experimentale des parametres de securite desproduits chimiques. Chimia, 2003, vol. 57, no. 12, pp. 766-769.

22. Strokova L.A., Ermolaeva A.V., Golubeva V.V. The investment of Dangerous Geological Processes Result in Land Subsidence While Designing the Main Gas Pipeline in South Yakutia. IOP Conference Series: Earth and Environmental Science, 2016, vol. 43, 6 p.

23. Strokova L.A. Modeling of tunnelinginduced ground surface mo vement / Scientific and Technical Challenges in the Well Drilling Progress. IOP Conference Series: Earth and Environmental Science, 2015, no. 24, 6 p.

24. Yang H., Xu X., Neumann I. Laser scanned updating of a financial element model for structural health monitoring. IEEE Sensor, 2016, vol. 7, pp. 2100-2104.

25. Yang H., Omidalizarandi M., Xu X., Neumann I.I. Terrestrial Laser Scanning Technology for Deformation Monitoring and Sur face Modeling of Arch Structures. Composite Structures, 2016, vol. 149, pp. 93-105.

26. Yardim Y., Mustafaraj E. Effects of soil settlement and deformed geometry on a historical structure. Natural hazard and Earth system Sciences, 2015, vol. 15, pp. 1051-1059.

27. Vacca G., Mistretta F., Stochino, F., Dessi A. Terrestrial laser scanner for monitoring the deformations and the damages of buildings. International Archives of the Photogrammetry, Remote Sensing \& Spatial Information Sciences, 2016, vol. 41, Iss. B5, pp. $453-460$.

28. Kuleshov A.P., Pendin V.V. Influence of the method for determining soil properties in numerical calculations of deformations. Bulletin of the Tomsk Polytechnic University. Geo Assets Engineering, 2017, vol. 328, no. 12, pp. 63-74. In Rus.

Received: 10 July 2018.

\section{Information about the authors}

Alexander P. Kuleshov, postgraduate, Sergo Ordzhonikidze Russian State Geological Prospecting University.

Vadim V. Pendin, Dr. Sc., professor, head of the department, Sergo Ordzhonikidze Russian State Geological Prospecting University. 